\title{
Relação entre polimorfismo do gene do receptor de prog̣esterona, raça, paridade e ocorrência de leiomioma uterino
}

\author{
Relation between progesterone receptor gene polymorphism, race, parity, \\ and uterine leiomyoma occurrence
}

\begin{abstract}
Mariano Tamura Vieira Gomes ${ }^{1}$, Rodrigo de Aquino Castro², Fabiola Elizabeth Villanova ${ }^{3}$, Ismael Dale Cotrim Guerreiro da Silva ${ }^{4}$ Edmund Chada Baracat ${ }^{5}$, Geraldo Rodrigues de Lima ${ }^{5}$, Manoel João Batista Castello Girão ${ }^{6}$
\end{abstract}

\section{RESUM0}

Objetivos: analisamos raça, paridade e presença do polimorfismo do gene do receptor de progesterona, denominado PROGINS, como fatores relacionados à ocorrência de leiomioma uterino em mulheres brasileiras. Métodos: realizamos estudo caso-controle, no qual foram incluídas 122 pacientes com diagnóstico de leiomioma e 125 mulheres sem a doença. Após registro dos dados clínicos, coletamos material biológico para extração de DNA, reação em cadeia da polimerase e eletroforese em gel de agarose, a fim de identificar a presença do polimorfismo PROGINS. A análise estatística foi feita pelo teste não paramétrico de Mann-Whitney ou pelo teste do $\chi^{2}$, a depender da variável estudada. O risco para ocorrência da doença foi calculado pelo modelo de regressão logística, com obtenção da odds ratio (OR) (razão de chances). O nível de significância adotado foi de 5\% (p<0,05) e o intervalo de confiança foi de 95\% (IC 95\%). Resultados: observamos maior prevalência de "não-brancas" - pardas e negras - (50 vs 22,4\%) e de nulíparas $(23,8$ vs 11,2\%) nos casos, ao passo que o genótipo do receptor de progesterona foi mais freqüentemente PROGINS positivo - heterozigoto ou homozigoto mutante - entre os controles $(21,6$ vs 10,7\%). A razão de chances indicou elevação do risco para leiomioma relacionada à raça "não branca" (OR=3,46; IC 95\%: 2,0-6,0) e à nuliparidade $(\mathrm{OR}=3,30$; IC 95\%: 1,9-5,6), com redução na presença de genótipos PROGINS positivo (OR=0,43; IC 95\%: 0,2-0,9). Conclusões: a raça "não branca" e a nuliparidade foram consideradas fatores de risco para a ocorrência de leiomioma uterino em mulheres da população estudada, ao passo que o polimorfismo PROGINS demonstrou ser fator protetor.

PALAVRAS-CHAVE: Leiomioma; Neoplasias uterinas; Fatores de risco; Receptor de progesterona; Polimorfismo; Grupos étnicos; Paridade

\section{ABSTRACT}

Purpose: to analyze race, parity and presence of the progesterone receptor polymorphism, named PROGINS, as factors related to uterine leiomyoma occurrence in Brazilian women. Methods: we carried out a case-control study, composed of 122 patients with the diagnosis of uterine fibroid and 125 women without the disease. After recording the clinical data, we collected biological material for DNA extraction, polymerase chain reaction and agarose gel electrophoresis in order to identify the presence of PROGINS polymorphism. Statistical analysis was performed using the non-parametric MannWhitney test or the $\chi^{2}$ test, depending on the studied variable. The risk for the occurrence of the disease was calculated by

Trabalho realizado no Departamento de Ginecologia da Universidade Federal de São Paulo - UNIFESP - São Paulo (SP), Brasil.

1 Pós-Graduando do Setor de Leiomioma Uterino do Departamento de Ginecologia da Universidade Federal de São Paulo - UNIFESP - São Paulo (SP), Brasil.

2 Assistente Responsável pelo Setor de Leiomioma Uterino do Departamento de Ginecologia da Universidade Federal de São Paulo - UNIFESP - São Paulo (SP), Brasil.

3 Biomédica Pós-Graduanda do Laboratório de Ginecologia Molecular do Departamento de Ginecologia da Universidade Federal de São Paulo - UNIFESP - São Paulo (SP), Brasil.

4 Professor Adjunto Livre Docente e Responsável pelo Laboratório de Ginecologia Molecular do Departamento de Ginecologia da Universidade Federal de São Paulo - UNIFESP - São Paulo (SP), Brasil.

5 Professor Titular do Departamento de Ginecologia da Universidade Federal de São Paulo - UNIFESP - São Paulo (SP), Brasil.

6 Professor Adjunto, Livre Docente e Chefe do Departamento de Ginecologia da Universidade Federal de São Paulo - UNIFESP - São Paulo (SP), Brasil. Correspondência: Mariano Tamura Vieira Gomes

Avenida Ibirapuera, 2907, conjunto 406 - 04029-200 - São Paulo - SP - Telefax: (11) 5042-4848 - e-mail: marianotvg@einstein.br 
the logistic regression model, providing the odds ratio (OR). The adopted significance level was $5 \%(\mathrm{p}<0.05)$ and the confidence interval was 95\% (95\% CI). Results: we observed a higher prevalence of "non-white" women - mulatto and black - (50 vs 22.4\%) and nulliparas (23.8 vs 11.2\%) in the cases, while the progesterone receptor genotype was more often PROGINS positive - heterozygous or mutant homozygous - among the controls (21.6 vs $10.7 \%)$. The OR indicated an elevated risk for leiomyoma related to the "non-white" race (OR=3.46; 95\% CI: 2.0-6.0) and the nulliparity (OR=3.30; 95\% CI: 1.9-5.6), with reduction in the presence of PROGINS-positive genotypes (OR=0.43; 95\% CI: 0.2-0.9). Conclusions: the "nonwhite" race and nulliparity were considered risk factors for the occurrence of uterine fibroid in the studied population, while PROGINS polymorphism showed to be a protective factor.

KEYWORDS: Leyomioma; Uterine neoplasms; Risk factors; Progesterone receptor; Polymorphism; Ethnical groups; Parity

\section{Introdução}

O leiomioma do útero, neoplasia benigna mais freqüente do aparelho reprodutor feminino na menacme, acomete pelo menos $30 \%$ das mulheres acima de 30 anos $^{1}$. Apresenta predisposição familiar - sendo mais prevalente entre parentes de primeiro grau em famílias com dois ou mais membros acometidos ${ }^{2}$ - e racial, com predomínio na raça negra ${ }^{1,3,4}$. Fatores reprodutivos parecem afetar o desenvolvimento dos leiomiomas, com aparente papel protetor da paridade ${ }^{5,6}$.

Embora o estrogênio seja visto como o mais importante promotor do crescimento tumoral, achados recentes mostram que a progesterona também estaria envolvida, atuando em combinação na patogênese da doença ${ }^{7}$. Evidências bioquímicas, histopatológicas e clínicas sugerem que a progesterona e os progestagênios, por meio dos respectivos receptores celulares, promovam a proliferação tumoral. Admite-se, também, que a taxa de mitose elevada propiciaria a propagação de mutações somáticas, cabendo à progesterona um papel crítico na sua modulação ${ }^{8}$.

O gene do receptor de progesterona (RP) em humanos é único e localiza-se no braço longo do cromossomo 11, nas bandas 22-23 (11q22-23), sendo responsável pela produção de duas isoformas protéicas: RP-A e RP-B ${ }^{9}$. Alelos mutantes desse gene foram descritos recentemente, destacandose o polimorfismo PROGINS, que consiste em uma inserção da família Alu de 306 pares de base (pb) no intron $\mathrm{G}$, entre os éxons 7 e 8 - região codificante do domínio de ligação hormonal. Essa inserção levaria à transcrição anômala do gene, codificando uma forma variante do éxon $8^{10,11}$. A codificação de um éxon alternativo, por sua vez, resultaria em perda da capacidade de ligação do hormônio ao receptor e da sua subseqüente ativação, com queda da atividade final mediada pela progesterona $^{12}$.

O polimorfismo PROGINS foi encontrado ape- nas em humanos, indicando que essa forma variante surgiu em nosso genoma somente após sua divergência de outros primatas. Comparando-se 21 grupos étnicos humanos diferentes, verificase maior freqüência de PROGINS entre gregos ciprióticos (22\%) e menor (zero) em dois grupos africanos, denominados !Kung e Nguni, com freqüência média do alelo polimórfico ou mutante de $11 \%$ e índice médio de heterozigose de $18,8 \%$ nas populações estudadas ${ }^{13}$.

A presença do PROGINS em mulheres com leiomioma foi previamente registrada em duas populações $^{14,15}$ - caucasianas italianas e chinesas -, não tendo sido encontrada associação positiva ou negativa do polimorfismo com a doença. Porém, por se tratar de afecção com etiologia multifatorial e comportamento biológico heterogêneo (em especial entre grupos étnicos distintos) ${ }^{1,4,16}$, não podemos descartar a possibilidade de que esse polimorfismo seja um marcador em populações com outras características.

Dessa maneira, avaliamos a relação de fatores como raça, paridade e presença do polimorfismo PROGINS com a ocorrência de leiomioma uterino em mulheres brasileiras.

\section{Métodos}

Desenvolvemos estudo caso-controle, após aprovação do Comitê de Ética em Pesquisa da Universidade Federal de São Paulo/Escola Paulista de Medicina (UNIFESP/EPM), e todas as participantes assinaram o termo de consentimento livre e esclarecido.

Selecionamos, para o Grupo Caso, $122 \mathrm{mu}-$ lheres atendidas no Setor de Leiomioma Uterino, com diagnóstico clínico (sangramento uterino anormal e/ou dor pélvica) e ultra-sonográfico da afecção e com indicação de tratamento cirúrgico devido à presença de sintomas. Todas foram submetidas à miomectomia ou histerectomia no Hos- 
pital São Paulo entre 2002 e 2004 e foi obtida confirmação diagnóstica histopatológica para todos os casos. O Grupo Controle foi composto por $125 \mathrm{mu}-$ lheres na pós-menopausa, com idade de quarenta e cinco anos ou mais, incluídas depois de avaliação clínica (ausência de dor pélvica e/ou sangramento uterino anormal pregresso ou atual) e ultrasonográfica, sem o diagnóstico de leiomioma.

Após registro de idade e paridade, as participantes submeteram-se à ultra-sonografia pélvica endovaginal, com observação dos aspectos ecotexturais e do volume uterino. Quanto à raça, foram inicialmente classificadas como brancas, pardas ou negras, de acordo com as características físicas (cor da pele e dos olhos, cor e tipo dos cabelos, formato do nariz e dos lábios), conforme previamente descrito ${ }^{17}$. Posteriormente, foram definitivamente classificadas apenas como brancas ou "não-brancas" - negras e pardas -, grupo assim denominado devido à marcante miscigenação racial, com herança genética africana altamente presente na população brasileira, tornando imprecisa a diferenciação de alguns grupos étnicos conforme o fenótipo ${ }^{17}$.

Para estudo do material biológico, retirouse, no Grupo Caso, fragmento de $1 \mathrm{~cm}^{3}$ do tumor durante histerectomia ou miomectomia, conservado a $-80^{\circ} \mathrm{C}$ até a extração de DNA. Para tal, colocou-se uma porção do leiomioma em $100 \mu \mathrm{L}$ de tampão de digestão contendo proteinase $\mathrm{K}$ e incubou-se esse material a $50^{\circ} \mathrm{C}$ por 12 horas. Então, a proteinase $\mathrm{K}$ foi inativada por 15 minutos a $70^{\circ} \mathrm{C}$ e seguiu-se com adição de $500 \mu \mathrm{L}$ do tampão de lise do kit GFX (Amersham Biosciences). A seguir, o lisado foi centrifugado a $8.000 \mathrm{rpm} / 4^{\circ} \mathrm{C}$ (Eppendorf modelo 5804 R), por um minuto, em coluna cromatográfica (sílica). Após duas etapas de lavagem e centrifugação com tampões contendo etanol, o DNA foi diluído em $100 \mu \mathrm{l} \mathrm{de} \mathrm{H}_{2} \mathrm{O}$ milli$\mathrm{Q}$ autoclavado e pré-aquecido a $70^{\circ} \mathrm{C}$. O DNA purificado foi armazenado a $-80^{\circ} \mathrm{C}$ até sua utilização. No Grupo Controle, foram coletados $5 \mathrm{~mL}$ de sangue em punção venosa periférica, utilizando vacutainer com anticoagulante (EDTA), seguido da extração imediata do DNA genômico, com o kit GFX (Amersham Biosciences), adicionando-se $500 \mu \mathrm{L}$ de tampão de lise em $100 \mu \mathrm{L}$ de sangue e realizando-se os mesmos procedimentos descritos para o Grupo Caso. A quantidade de DNA foi medida por espectrofotometria $(260 \mathrm{~nm})$ de alíquotas do DNA purificado, em equipamento Spectronic, modelo Genesys 5. Reações em cadeia da polimerase (PCR) feitas com oligonucleotídeos (primers) para a $\beta$ globina foram usadas como controles positivos para verificar a qualidade do DNA e a eficiência da amplificação ${ }^{18}$.
Nas reações de amplificação do gene do RP foram utilizados os seguintes primers - senso: 5 ' GGC AGA AAG CAA AAT AAA AAG A 3', anti-senso: 5' AAA GTA TTT TCT TGC TAA ATG TC 3'11,19. Foi utilizado $1 \mu \mathrm{L}$ do DNA total em um volume final de $25 \mu \mathrm{L}$ de reação, contendo $1 \mu \mathrm{L}$ de cada primer $(0,4$ $\mathrm{pmol} / \mu \mathrm{L})$ e $22 \mu \mathrm{L}$ de mix Promega $(20 \mathrm{mM}$ de Tris$\mathrm{HCl}, \mathrm{pH}$ 8.4, $50 \mathrm{mM}$ de $\mathrm{KCl}, 5 \mathrm{mM}$ de $\mathrm{MgCl}_{2}, 200 \mu \mathrm{M}$ de dNTPs e 1,25 U de Taq DNA polimerase). As reações foram incubadas em termociclador (GeneAmp PCR System 9700 - Perkin Elmer) nas seguintes condições: desnaturação a $94^{\circ} \mathrm{C}$ durante cinco minutos, seguida de 40 ciclos a $94^{\circ} \mathrm{C}$ por um minuto (desnaturação), $55^{\circ} \mathrm{C}$ por um minuto (hibridação dos oligonucleotídeos) e $72^{\circ} \mathrm{C}$ por um minuto (polimerização), finalizados com incubação a $72^{\circ} \mathrm{C}$ por cinco minutos. Os produtos obtidos foram aplicados em gel de agarose a $2 \%$, corado com brometo de etídeo $(1 \mu \mathrm{g} / \mathrm{mL}$, e submetidos à eletroforese por 20 minutos a 100 volts, numa cuba horizontal contendo tampão de corrida TBE 1X. Pela visualização em transiluminador de luz ultravioleta, foram detectados os produtos de PCR no gel de agarose, os quais poderiam apresentar dois tamanhos, segundo a presença ou a ausência da inserção Alu PV/HS-1 de 306 pb no íntron $\mathrm{G}$, entre os éxons 7 e 8, denominada PROGINS. Quando o alelo do receptor de progesterona não apresentava tal inserção, tínhamos um fragmento de $149 \mathrm{pb}$, representando a forma selvagem (T1). Quando o alelo apresentava a inserção, o fragmento obtido era de $455 \mathrm{pb}$, correspondendo à forma mutante ou polimórfica (T2) (Figura 1) ${ }^{11,20}$.

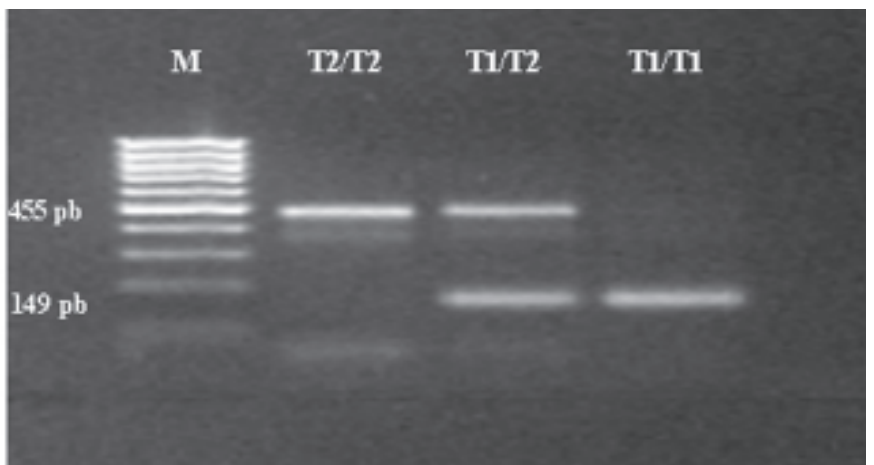

Figura 1 - Gel de agarose a $2 \%$, corado com brometo de etídeo para visualização dos produtos de PCR amplificados a partir do gene do receptor de progesterona. $\mathrm{Na}$ coluna $\mathrm{M}$ temos o marcador. A coluna T2/T2 representa o genótipo homozigoto mutante, com dois fragmentos de $455 \mathrm{pb}$. Na coluna T1/T2 temos o genótipo heterozigoto, com a presença de um alelo de $149 \mathrm{pb}$ e outro de $455 \mathrm{pb}$. A coluna $\mathrm{T} 1 / \mathrm{T} 1$ representa o genótipo homozigoto selvagem, com dois fragmentos de 149 $\mathrm{pb}$ 
A partir da freqüência alélica encontrada na população estudada, verificamos se a distribuição genotípica respondia à lei de Hardy-Weinberg. Tal lei pode ser usada para calcular se determinada amostra representa uma população em equilíbrio genético e que atende a certas suposições (reprodução aleatória, taxa pequena de mutações e ausência de seleção contra algum genótipo particular no locus de interesse) e, para isso, utiliza-se uma fórmula matemática ${ }^{21}$. A seguir, comparamos a presença de genótipos PROGINS positivos (heterozigoto e homozigoto mutante) e PROGINS negativo (homozigoto selvagem) entre casos e controles. Devido ao número muito pequeno de homozigotos mutantes em nossa casuística, esses foram avaliados em conjunto com os heterozigotos, a fim de permitir análise estatística.

Finalmente, aplicamos o teste não paramétrico de Mann-Whitney para estudo das variáveis contínuas (idade, volume uterino) e o teste de freqüências do $\chi^{2}$ para estudo das variáveis categóricas (raça, paridade, genótipo do RP). O nivel de significância adotado foi de 5\% $(p<0,05)$ e a razão de chances, ou odds ratio (OR), foi calculada pelo modelo de regressão logística, com intervalo de confiança de 95\% (IC 95\%). Utilizamos, para os testes estatísticos, o software STATA, versão 7.0.

\section{Resultados}

A média de idade do Grupo Caso foi $43,9 \pm 7,3$ anos e do Grupo Controle foi 56,9 $9 \pm 7,4$ anos (p<0,001). Quanto à raça, 50\% dos casos e 77,6\% dos controles foram classificados como brancas, ao passo que a proporção de "não-brancas" (pardas e negras) foi de $50 \%$ entre os casos e de $22,4 \%$ entre os controles $(p<0,0001)$. O Grupo Caso foi composto por $23,8 \%$ de nulíparas e o Grupo Controle por $11,2 \%(\mathrm{p}<0,0001)$. O volume uterino médio à ultra-sonografia foi $429,8 \pm 293,4 \mathrm{~cm}^{3}$ para os casos e $38,1 \pm 21,7 \mathrm{~cm}^{3}$ para os controles $(\mathrm{p}<0,0001)$. Os genótipos PROGINS positivos (heterozigoto + homozigoto mutante) estiveram presentes em $10,7 \%$ dos casos e em $21,6 \%$ dos controles $(\mathrm{p}=0,020)$ (Tabela 1). A distribuição genotípica manteve-se em equilíbrio de Hardy-Weinberg considerando-se toda a casuística, assim como nos Grupos Caso e Controle. Não encontramos associação das variáveis raça ou paridade com os diferentes genótipos do receptor de progesterona, quando avaliados apenas os controles (Tabela 2).
Tabela 1 - Distribuição das variáveis clínicas e do genótipo do receptor de progesterona (RP) quanto ao polimorfismo PROGINS, de acordo com o grupo.

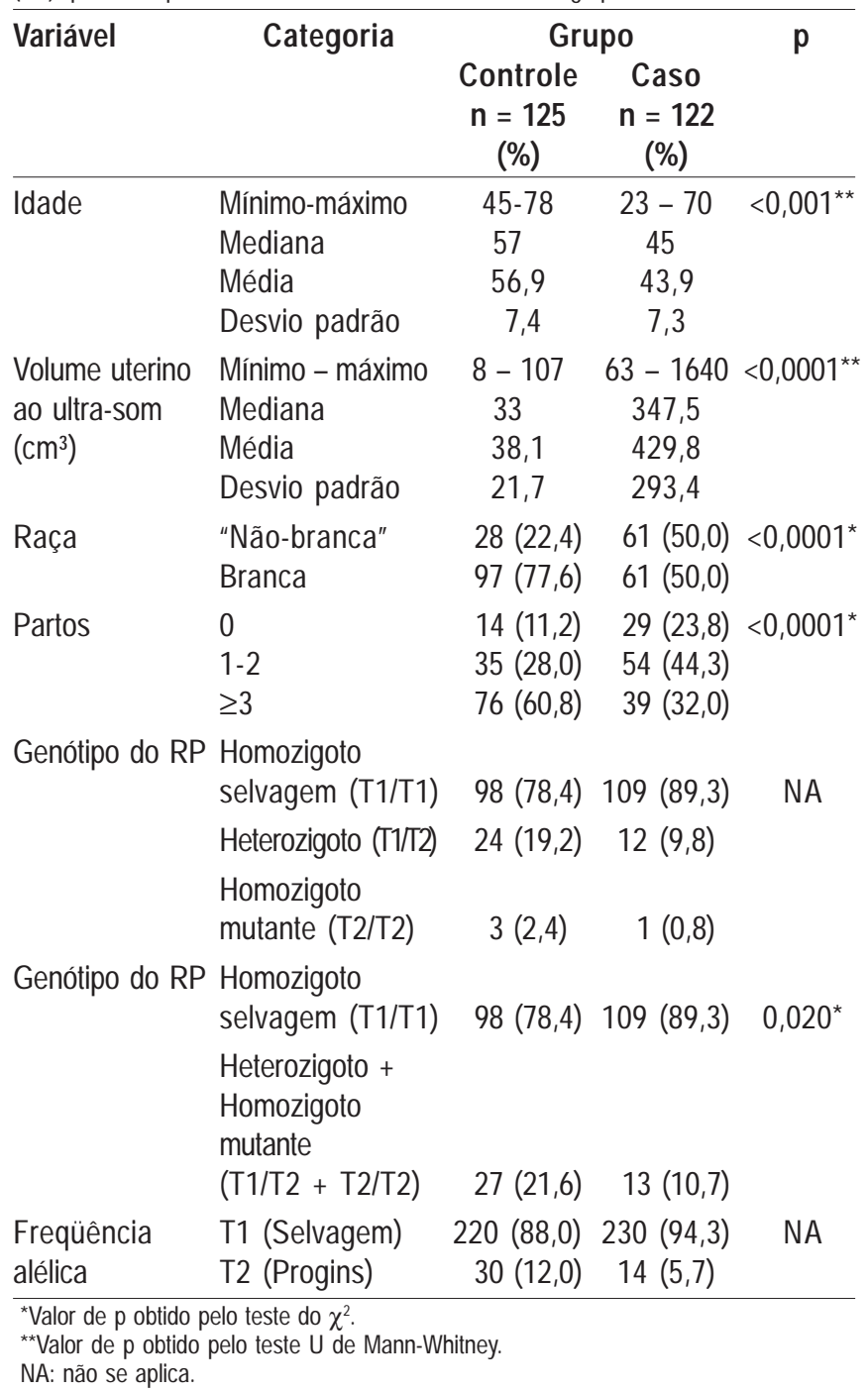

Tabela 2 - Distribuição das variáveis clínicas, de acordo com o genótipo do receptor de progesterona (RP) quanto ao polimorfismo PROGINS, para os controles.

\begin{tabular}{llccc}
\hline Variável Categoria & \multicolumn{3}{c}{$\begin{array}{c}\text { Genótipo do RP } \\
\text { Homozigoto } \\
\text { selvagem } \\
\text { (T1/T1) }\end{array}$} & $\begin{array}{c}\text { Heterozigoto + } \\
\text { homozigoto } \\
\text { mutante }\end{array}$ \\
& & $\mathbf{n}=207(\%)$ & $\begin{array}{c}\text { (T1/T2 + T2/T2) } \\
\text { n = 40 (\%) }\end{array}$ \\
\hline Raça & Branca & $77(78,6)$ & $20(74,1)$ & $0,620^{*}$ \\
& "Não-branca" & $21(21,4)$ & $7(25,9)$ & \\
Partos & $0-2$ & $37(37,8)$ & $12(44,4)$ & $0,528^{*}$ \\
& 23 & $61(62,2)$ & $15(55,6)$ & \\
\hline
\end{tabular}

*Valor de p obtido pelo teste do $\chi^{2}$ 
O cálculo da razão de chances (OR) para leiomioma uterino demonstrou diminuição do risco associada aos genótipos PROGINS positivos (heterozigoto + homozigoto mutante) (OR $=0,43$; IC 95\%: $0,2-0,9 ; \mathrm{p}=0,022)$ e aumento relacionado à raça "não-branca" $(\mathrm{OR}=3,46$; IC 95\%: 2,0-6,0; $\mathrm{p}<0,001)$ e à nuliparidade (OR=3,30; IC 95\%: 1,95,6; p<0,001) (Tabela 3).

Tabela 3 - Razão de chances para a ocorrência de leiomioma uterino.

\begin{tabular}{llcc}
\hline Variável & Categoria & OR (IC 95\%) & p \\
\hline Genótipo do RP & $\begin{array}{l}\text { Homozigoto selvagem } \\
\text { (T1/T1)Heterozigoto }+ \\
\text { homozigoto mutante } \\
(\mathrm{T} 1 / \mathrm{T} 2+\mathrm{T} 2 / \mathrm{T} 2)\end{array}$ & & \\
& $\geq 1$ & $1,00,43(0,2-0,9)$ & 0,022 \\
Partos & 0 & $1,03,30(1,9-5,6)$ & $<0,001$ \\
Raça & Branca & $1,03,46(2,0-6,0)$ & $<0,001$ \\
& "Não-branca" & & \\
\hline
\end{tabular}

$\mathrm{RP}=$ receptor de progesterona; OR = odds ratio; IC 95\% = intervalo de confiança a 95\%. Valor de $\mathrm{p}$ obtido pelo teste $\chi^{2}$

\section{Discussão}

A raça tem sido considerada importante fator de risco para leiomiomas. As negras têm probabilidade maior de ter a doença e tendem a ser mais jovens que as brancas no momento do diagnóstico e da cirurgia ${ }^{4}$. Além disso, foram encontrados nódulos maiores, mais numerosos e mais sintomáticos em negras, a despeito da idade mais jovem no momento do diagnóstico e do tratamento $^{16}$. A maior incidência da doença em negras ocorre entre 35 e 39 anos e, em brancas, entre 40 e 44 anos, com maiores pesos uterinos e maior probabilidade de anemia nas primeiras ${ }^{1}$. Em nossa casuística, confirmamos maior prevalência de leiomioma uterino em brasileiras "não-brancas" (pardas e negras), com risco semelhante ao previamente observado para afro-americanas ${ }^{1,3,4}$, sugerindo a presença de fatores intrínsecos comuns nessas populações.

O histórico reprodutivo também parece afetar o risco para leiomiomas. A associação de nuliparidade com a doença, verificada em nosso estudo, está de acordo com os resultados obtidos na pesquisa realizada pela Oxford Family Planning Association Cohort Studies, que sugeriu relação inversa entre o número de gestações a termo e a ocorrência de leiomioma ${ }^{5}$, assim como o estudo prospectivo com coortes de negras americanas, que confirmou a mesma relação nesse grupo étnico ${ }^{22}$. No entanto, os mecanismos pelos quais a paridade exerce seu papel protetor permanecem desconhecidos, merecendo investigação pormenorizada.

Em decorrência do papel dos esteróides sexuais no controle do metabolismo miometrial, variações gênicas relacionadas à atuação desses hormônios têm importância para o entendimento dos leiomiomas uterinos. Como se sabe, a progesterona e os progestagênios agem nas células por meio dos seus receptores (RP-A e RP-B), originados de um único gene ${ }^{23,24}$. Um dos polimorfismos desse gene, denominado PROGINS, leva à codificação de um éxon 8 alternativo e, conseqüentemente, à expressão de uma forma aberrante dos receptores de progesterona, com propriedades alteradas de interação protéica e regulação hormonal, assim como perda da capacidade de ligação e ativação transcricional em resposta à progesterona ${ }^{20}$. Tem sido proposto que os homodímeros do RP-B mediariam a ação hormonal, ao passo que a variante truncada RP-A teria atividade repressora da transcrição ${ }^{25-27}$. Dessa maneira, Fabjani et al. (2002) ${ }^{28}$, sugeriram que a isoforma RP-A, quando associada ao PROGINS, teria sua estabilidade elevada, reprimindo com maior intensidade a ação mediada pelo RP-B nos genes-alvo.

Os polimorfismos são variações genéticas herdadas, presentes em todas as células (germinativas ou somáticas, sadias ou doentes) e com prevalência variável em diferentes populações. Por isso, qualquer linhagem celular amplificada seria representativa para estudo do organismo. No entanto, alterações cromossômicas e mutações gênicas podem ocorrer nas células somáticas, em especial nos tumores. Deleções, translocações e rearranjos conhecidos, envolvendo os cromossomos 3, 6, 7, 10, 12 e 14, são encontrados em até $40 \%$ dos leiomiomas ${ }^{29,30}$. Isso não invalida nossa escolha de tecido tumoral como material de estudo no Grupo Caso, pois tais alterações, quando presentes, não acometem todas as células de determinado nódulo ${ }^{31}$, e poupam o cromossomo 11 (sede do gene RP). Ainda assim, caso houvesse alterações somáticas nas células tumorais estudadas, envolvendo o fragmento amplificado no estudo molecular do gene RP, esperar-seia desvio do equilíbrio de Hardy-Weinberg na distribuição genotípica dos casos, com redução dos genótipos heterozigotos quando da eliminação de um dos alelos, ou não visualização das bandas após eletroforese no gel de agarose quando da eliminação dos dois alelos (o que não aconteceu com nenhuma participante). Se houvesse uma mutação somática específica no tecido neoplásico, com a inserção de 306 pb da família Alu - geradora do alelo polimórfico PROGINS -, teríamos maior prevalência dessa variante nos casos em relação aos 
controles, e não menor, como foi de fato encontrada. Além disso, devemos destacar que o produto da amplificação por PCR não representa apenas o DNA das células tumorais, pois envolve o DNA de leucócitos, fibroblastos e células miometriais normais, também presentes na amostra tecidual. Comparações prévias sobre a presença simultânea de polimorfismos no sangue, miométrio ou leiomioma foram feitas por outros autores ${ }^{32,33}$, não tendo sido encontradas diferenças nesses tecidos, fortalecendo a convicção de que o DNA por nós obtido oferece resultados confiáveis e representativos das células do organismo.

Compor os controles com mulheres na pósmenopausa, assintomáticas e com rastreamento ultra-sonográfico negativo nos fornece a melhor aproximação de um grupo verdadeiramente não afetado pelo leiomioma uterino e sem risco de desenvolver a doença no futuro. Embora o exame clínico e ultra-sonográfico não sejam capazes de excluir completa e inequivocamente a ocorrência da neoplasia, uma vez que lesões microscópicas podem existir, deve-se notar que a eventual presença de mulheres com leiomioma no grupo controle diminuiria as chances de encontrarmos associação (positiva ou negativa) entre o polimorfismo e a afecção. Isso torna o resultado obtido ainda mais relevante. Com o objetivo de determinar se certas características clínicas poderiam associarse ao PROGINS, gerando vieses de resultados, avaliamos as variáveis raça e paridade quanto ao genótipo do RP no Grupo Controle, não encontrando qualquer relação. Os casos foram propositalmente excluídos dessa análise, a fim de evitar possíveis associações devidas à doença.

A presença do PROGINS foi previamente registrada entre caucasianas italianas e chinesas. Não se observou diferença entre pacientes com leiomioma e controles. Vale ressaltar, como registrado pelos autores do estudo italiano, que seus resultados não podem ser estendidos para outros grupos étnicos, nem excluir a possibilidade de que esse polimorfismo seja um marcador de risco ou de proteção em populações com outras características $^{14}$. Quanto ao estudo de Hsieh et al. ${ }^{15}$, chama a atenção que a população escolhida como controle encontrava-se na menacme, com risco de desenvolver a doença futuramente, reduzindo a precisão dos resultados apresentados.

Encontramos no alelo PROGINS um marcador de proteção para leiomioma entre as brasileiras e os novos resultados indicam que esse polimorfismo pode proteger as mulheres por meio de repressão à ação da progesterona nos genesalvo. No entanto, como esta pesquisa é a primeira a apontar a existência dessa relação, estudos di- ferenciando o risco em diferentes grupos étnicos são fundamentais, assim como investigações que esclareçam definitivamente o papel biológico do PROGINS, pois a associação (proteção ou risco) de certos alelos com determinada doença não traduz, necessariamente, uma ligação etiológica. Supondo que a presença do alelo PROGINS seja realmente protetora, seria também interessante realizar um estudo com casuística suficientemente grande para que pudéssemos analisar separadamente o papel do genótipo homozigoto mutante (pouco prevalente), verificando se o mesmo oferece proteção maior que o genótipo heterozigoto.

Trabalho financiado pela Fundação de Amparo à Pesquisa do Estado de São Paulo (FAPESP), processo 03/04533-1

\section{Referências}

1. Marshall LM, Spiegelman D, Barbieri RL, Goldman MB, Manson JE, Colditz GA, et al. Variation in the incidence of uterine leiomyoma among premenopausal women by age and race. Obstet Gynecol. 1997;90(6):967-73.

2. Vikhlyaeva EM, Khodzhaeva ZS, Fantschenko ND. Familial predisposition to uterine leiomyomas. Int J Gynaecol Obstet. 1995;51(2):127-31.

3. Cramer DW. Epidemiology of myomas. Semin Reprod Endocrinol. 1992;10(4):320-4.

4. Kjerulff KH, Guzinski GM, Langenberg PW, Stolley PD, Moye NE, Kazandjian VA. Hysterectomy and race. Obstet Gynecol. 1993;82(5):757-64.

5. Ross RK, Pike MC, Vessey MP, Bull D, Yeates D, Casagrande JT. Risk factors for uterine fibroids: reduced risk associated with oral contraceptives. Br Med J (Clin Res Ed). 1986;293(6543):359-62.

6. Parazzini F, La Vecchia C, Negri E, Cecchetti G, Fedele L. Epidemiologic characteristics of women with uterine fibroids: a case-control study. Obstet Gynecol. 1988;72(6):853-7.

7. Rein MS. Advances in uterine leiomyoma research: the progesterone hypothesis. Environ Health Perspect. 2000;108 Suppl 5:791-3.

8. Rein MS, Barbieri RL, Friedman AJ. Progesterone: a critical role in the pathogenesis of uterine myomas. Am J Obstet Gynecol. 1995;172(1 Pt 1):148.

9. Rousseau-Merck MF, Misrahi M, Loosfelt H, Milgrom E, Berger R. Localization of the human progesterone receptor gene to chromosome 11q22q23. Hum Genet. 1987;77(3):280-2. 
10. McKenna NJ, Kieback DG, Carney DN, Fanning M, McLinden J, Headon DR. A germline TaqI restriction fragment length polymorphism in the progesterone receptor gene in ovarian carcinoma. $\mathrm{Br} \mathrm{J}$ Cancer. 1995;71(3):451-5.

11.Wieser F, Scheneeberger C, Tong D, Tempfer C, Huber JC, Wenzl R. PROGINS receptor gene polymorphism is associated with endometriosis. Fertil Steril. 2002;77(2):309-12.

12. Vegeto E, Allan GF, Schrader WT, Tsai MJ, McDonnell DP, O'Malley BW. The mechanism of RU 486 antagonism is dependent on the conformation of the carboxy-terminal tail of the human progesterone receptor. Cell. 1992;69(4):703-13.

13. Donaldson CJ, Crapanzano JP, Watson JC, Levine EA, Batzer MA. PROGINS Alu insertion and human genomic diversity. Mutat Res. 2002;501(1-2):137-41.

14. Massart F, Becherini L, Marini F, Noci I, Piciocchi $\mathrm{L}$, Del Monte F, et al. Analysis of estrogen receptor (ERa and $\mathrm{ERb}$ ) and progesterone receptor (PR) polymorphisms in uterine leiomyomas. Med Sci Monit. 2003;9(1):BR25-30.

15. Hsieh YY, Chan IP, Wang HI, Chang CC, Huang CW, Lin CS. PROGINS Alu sequence insertion is associated with hyperprolactinaemia but not leiomyoma susceptibility. Clin Endocrinol (Oxf). 2005;62(4):492-7.

16. Kjerulff KH, Langenberg P, Seidman JD, Stolley PD, Guzinski GM. Uterine leiomyomas: racial differences in severity, symptoms and age at diagnosis. J Reprod Med. 1996;41(7):483-90.

17. Parra FC, Amado RC, Lambertucci JR, Rocha J, Antunes CM, Pena SD. Color and genomic ancestry in Brazilians. Proc Natl Acad Sci U S A. 2003;100(1):177-82.

18. Gattas GJ, Soares-Vieira JA. Cytochrome P450-2E1 and glutathione S-transferase polymorphisms among Caucasians and mulattoes from Brazil. Occup Med (Lond). 2000;50(7):508-11.

19. Lancaster JM, Berchuck A, Carney ME, Wiseman $\mathrm{R}$, Taylor JA. Progesterone receptor gene polymorphism and risk for breast and ovarian cancer. Br J Cancer. 1998;78(2):277.

20. Rowe SM, Coughlan SJ, McKenna NJ, Garret E, Kieback DG, Carney DN, et al. Ovarian carcinomaassociated TaqI restriction fragment length polymorphism in intron $\mathrm{G}$ of the progesterone receptor gene is due to an Alu sequence insertion. Cancer Res. 1995;55(13):2743-5.

21. Nussbaum RL, McInnes RR, Willard HF. Thompson $\&$ Thompson genetics in medicine. $6^{\text {th }}$ ed. Philadelphia: W.B. Saunders; 2001.

22.Wise LA, Palmer JR, Harlow BL, Spiegelman D, Stewart EA, Adams-Campbell LL, et al. Reproductive factors, hormonal contraception, and risk of uterine leiomyomata in African-American women: a prospective study. Am J Epidemiol. 2004;159(2):11323.

23. Kastner P, Krust A, Turcotte B, Stropp U, Tora L, Gronemeyer $\mathrm{H}$, et al. Two distinct estrogen-regulated promoters generate transcripts encoding the two functionally different human progesterone receptor forms A and B. EMBO J. 1990;9(5):1603-14.

24. Misrahi M, Venencie PY, Saugier-Veber P, Sar S, Dessen P, Milgrom E. Structure of the human progesterone receptor gene. Biochim Biophys Acta. 1993;1216(2):289-92.

25. Vegeto E, Shahbaz MM, Wen DX, Goldman ME, O'Malley BW, McDonnell DP. Human progesterone receptor A form is a cell- and promoter-specific repressor of human progesterone receptor $B$ function. Mol Endocrinol. 1993;7(10):1244-55.

26. Attia GR, Zeitoun K, Edwards D, Johns A, Carr BR, Bulun SE. Progesterone receptor isoform A but not $\mathrm{B}$ is expressed in endometriosis. J Clin Endocrinol Metab. 2000;85(8):2897-902.

27. Mulac-Jericevic B, Mullinax RA, DeMayo FJ, Lydon JP, Coneely OM. Subgroup of reproductive functions of progesterone mediated by progesterone receptorB isoform. Science. 2000;289(5485):1751-4.

28. Fabjani G, Tong D, Czerwenka K, Schuster E, Speiser $\mathrm{P}$, Leodolter S, et al. Human progesterone receptor gene polymorphism PROGINS and risk for breast cancer in Austrian women. Breast Cancer Res Treat. 2002;72(2):131-7.

29. Rein MS, Friedman AJ, Barbieri RL, Pavelka K, Fletcher JA, Morton CC. Cytogenetic abnormalities in uterine leiomyomata. Obstet Gynecol. 1991;77(6):923-6.

30. Mantovani MS, Neto JB, Philbert PM, Casartelli C. Multiple uterine leiomyomas: cytogenetic analysis. Gynecol Oncol. 1999;72(1):71-5.

31. Marshal RD, Fejzo ML, Friedman AJ, Mitchner N, Nowak RA, Rein MS, et al. Analysis of androgen receptor DNA reveals the independent clonal origins of uterine leiomyomata and the secondary nature of cytogenetic aberrations in the development of leiomyomata. Genes Chromosomes Cancer. 1994;11(1):1-6.

32. Gloudemans T, Pospiech I, Van der Ven LT, Lips CJ, Den Otter W, Sussenbach JS. An avaII restriction fragment length polymorphism in the insulin-like growth factor II gene and the occurrence of smooth muscle tumors. Cancer Res. 1993;53(23):5754-8.

33.Al-Hendy A, Salama SA. Catechol-Omethyltransferase polymorphism is associated with increased uterine leiomyoma risk in different ethnic groups. J Soc Gynecol Investig. 2006;13(2):136-44. 